\title{
Upaya Mitigasi Bencana Melalui Aplikasi Dayakan Mitigation Center (DMC)
}

\author{
Ardhana Januar Mahardhani ${ }^{1 *}$, Iqbal Akbar Imamudin ${ }^{1}$, Fendy Eko Hardiawan ${ }^{1}$ \\ ${ }^{I}$ Fakultas Keguruan dan Ilmu Pendidikan, Universitas Muhammadiyah Ponorogo \\ Jalan Budi Utomo No 10, Ronowijayan, Siman, Ponorogo, Jawa Timur 63471 \\ Email Penulis Korespodensi: ardhana@umpo.ac.id
}

\begin{abstract}
Dayakan Village is one of the villages located in Badegan Subdistrict, Ponorogo Regency, East Java Province with a topographical condition of $80 \%$ of the plateau, as a result, this village is hit by disasters every year. The existence of various disasters that hit Dayakan Village made a team from the Teaching and Education Faculty make an application in the context of disaster mitigation, namely the Dayakan Mitigation Center (DMC). This paper is the result of the dedication carried out in the context of introducing the DMC application as one of the disaster management efforts in Dayakan Village and making Dayakan Village a Smart Village. Implementing this activity is a team from the Teaching and Education Faculty, Muhammadiyah University of Ponorogo in collaboration with the Dayakan Village Government, the Dayakan Village Youth Organization, and the Dayakan Village Disaster Preparedness Youth Team (Tagana). The steps taken in this activity are (a) Program Socialization, (b) Formation of the DMC Team (c) Making DMC Applications, (d) Introduction to Application Use, (e) Workshop and Application Launching, and $(f)$ Evaluation and Monitoring. From the implementation of the activities, it is known that there is a need for intense and sustainable collaboration between various parties to sustain the use of the DMC application by the Dayakan Village community. As of December 31, 2020, it is known that 45 people have registered as new users in the DMC application.
\end{abstract}

Keywords: Applications, Disasters, Mitigation

\begin{abstract}
Abstrak
Desa Dayakan merupakan salah satu desa yang terletak di Kecamatan Badegan Kabupaten Ponorogo Provinsi Jawa Timur dengan kondisi topografis $80 \%$ adalah dataran tinggi, akibatnya desa ini setiap tahun dilanda dengan bencana. Adanya berbagai bencana yang melanda Desa Dayakan menjadikan tim dari Fakultas Keguruan dan Ilmu Pendidikan membuat aplikasi dalam rangka bentuk mitigasi bencana yaitu Dayakan Mitigation Center (DMC). Tulisan ini merupakan hasil pengabdian yang dilakukan dalam rangka pengenalan aplikasi DMC sebagai salah satu upaya penanggulangan bencana yang ada di Desa Dayakan dan menjadikan Desa Dayakan sebagai Smart Village. Pelaksana dari kegiatan ini adalah tim dari Fakultas Keguruan dan Ilmu Pendidikan Universitas Muhammadiyah Ponorogo bekerjasama dengan Pemerintah Desa Dayakan, Karang Taruna Desa Dayakan, dan Tim Taruna Siaga Bencana (Tagana) Desa Dayakan. Langkah yang dilakukan dalam kegiatan ini adalah (a) Sosialisasi Progam, (b) Pembentukan Tim DMC (c) Pembuatan Aplikasi DMC, (d) Pengenalan Penggunaan Aplikasi, (e) Lokakarya dan Launching Aplikasi, dan (f) Evaluasi dan Monitoring. Dari pelaksanaan kegiatan diketahui bahwa dibutuhkan adanya kolaborasi secara intens dan berkelanjutan antara berbagai pihak dalam rangka keberlanjutan penggunaan aplikasi DMC oleh masyarakat Desa Dayakan. Sampai dengan tanggal 31 Desember 2020 diketahui bahwa 45 orang telah teregister dalam pengguna baru di aplikasi DMC.
\end{abstract}

Kata kunci: Aplikasi, Bencana, Mitigasi 


\section{PENDAhUluan}

Pewujudan desa tangguh bencana saat ini menjadi keharusan, dengan kondisi alam yang tidak bisa diprediksi mengharuskan setiap desa selalu siap siaga dalam menghadapi segala kemungkinan. Kesiapsiagaan desa dan aparatur yang ada di dalamnya harus lebih sigap dan dinamis pada saat menghadapi segala bencana yang datang (Oktari, 2019). Oleh karenanya diperlukan adanya mitigasi sedini mungkin dalam meminimalisir bahaya bencana yang datang. Menurut Peraturan Pemerintah Nomor 21 Tahun 2008 tentang Penyelenggaraan Penanggulangan Bencana, pasal 1 ayat 6 bahwa mitigasi bencana adalah serangkaian upaya untuk mengurangi risiko bencana, baik melalui pembangunan fisik maupun penyadaran dan peningkatan kemampuan menghadapi ancaman bencana (Peraturan Pemerintah RI No 21 Tahun 2008, n.d.)

Kesiapsiagaan terhadap penanggulangan bencana ini menjadi pekerjaan rumah pada setiap daerah, terutama pada daerah yang berpotensi besar karena berada pada kawasan yang rawan. Desa Dayakan Kecamatan Badegan Kabupaten Ponorogo Kabupaten Ponorogo merupakan daerah yang pada setiap tahunnya berpotensi untuk terkena bencana hal ini dikarenakan morfologi tanah di Desa Dayakan mayoritas adalah dataran tinggi dengan gugusan pegunungan karts selatan Jawa. Luas Desa Dayakan adalah 958,987 Ha, dengan penggunaan lahan untuk pemukiman penduduk $55,808 \mathrm{Ha}$, lahan kering 551,892 Ha, dan untuk persawahan 351,287 Ha. Kondisi topografi di Desa Dayakan adalah dataran rendah seluas 196,191 Ha dan dataran tinggi 762,796 Ha.

Kondisi topografi Desa Dayakan memunculkan kemungkinan besar terjadinya bencana alam di daerah tersebut. Selain bencana alam, bencana non alam juga sering terjadi, seperti adanya konflik antar masyarakat. Mitigasi bencana perlu dilakukan untuk menekan resiko terjadinya bencana dan munculnya korban akibat terjadinya bencana. Mitigasi bencana tidak hanya menjadi tanggungan Badan Penanggulangan Bencana Daerah (BPBD) selaku lembaga penanggulangan bencana daerah, tetapi peran aktif masyarakat dalam memitigasi bencana juga perlu ditingkatkan.

Ancaman bencana di Desa Dayakan yang dimaksud adalah dalam Tabel 1 berikut.
Tabel 1. Ancanaman Bencana Desa Dayakan

\begin{tabular}{ll}
\hline \multicolumn{1}{c}{ Jenis Ancaman } & \multicolumn{2}{c}{ Ragam Bencana } \\
\hline Geogologi & $\begin{array}{l}\text { Gempa Bumi, Gerakan } \\
\text { Tanah, Tanah Longsor } \\
\text { Hidrometeorologi } \\
\text { Kekeringan, angin } \\
\text { putting beliung }\end{array}$ \\
Wabah malaria, \\
hama/penyakit tanaman, \\
penyakit hewan ternak \\
Kingkungan & $\begin{array}{l}\text { Kebakaran hutan, air } \\
\text { tercemar } \\
\text { Sosial }\end{array}$ \\
\hline
\end{tabular}

Sumber. (BPBD Kabupaten Ponorogo, 2020)

Pada tahun 2020 setidaknya beberapa bencana diantaranya pada bulan Januari terdapat masalah kekeringan (Wicaksono, 2020), pada bulan Maret terdapat banjir bandang dan tanah longsor (Badan Geologi, 2020; Mukharomah, 2020; Pebrianti, 2020), dan adanya bencana wabah Covid-19 yang telah menjadi Pandemi di seluruh dunia (Mahardhani, 2020).

Berdasarkan permasalahan yang terjadi di Desa Dayakan tersebut, maka kami mengadakan kegiatan pengabdian kepada masyarakat. Tujuan dari kegiatan pengabdian berupa pembinaan dan pemberdayaan desa ini adalah: (a) Mengedukasi masyarakat dalam mitigasi bencana di Desa Dayakan Kecamatan Badegan Kabupaten Ponorogo melalui aplikasi Dayakan Mitigation Center (DMC) yang dapat diakses oleh seluruh masyarakat Desa Dayakan baik dari dalam atau luar desa, (b) Meningkatkan peran masyarakat dalam hal mitigasi bencana sebagai upaya menuju desa tangguh bencana Desa Dayakan Kecamatan Badegan Kabupaten Ponorogo melalui pembentukan komunitas internal, (c) Menjadikan Desa Dayakan Kecamatan Badegan Kabupaten Ponorogo sebagai desa tangguh bencana dengan memanfaatkan teknologi informasi dan peran aktif masyarakat yang nantinya dapat dilihat melalui beberapa indikator seperti: kecepatan informasi adanya bencana, hubungan antar sektor, dan kemudahan akses penanganan adanya bencana yang hal tersebut pastinya akan memperkecil konflik antar masyarakat.

Penggunaan aplikasi dalam penanggulangan bencana bukan merupakan sesuatu yang baru (Muhammad et al., 2018; Sukirman et al., 2019; Sutedi, 2020), meskipun demikian implementasinya tidak bisa disamakan karena tergantung dengan keadaan sumberdaya manusia dan topografi wilayah yang ada (Ruswandi et al., 2008), yang bisa dipastikan 
adalah adanya aplikasi ini akan dapat mengurangi korban yang timbul dari sebuah bencana (Pratomo, 2019).

\section{METODE}

Dalam kegiatan pengabdian masyarakat ini akan memberikan sebuah inovasi dibidang teknologi informasi untuk memberikan pengetahuan, pemahaman, dan pengumuman terkait sistem informasi mengenai kebencanaan di Desa Dayakan. Inovasi yang dimaksud adalah berbasis aplikasi di smartphone yaitu aplikasi DMC

\section{Waktu dan Tempat Pelaksanaan}

Kegiatan pengabdian ini dilaksanakan pada 1 Juli 2020 sampai dengan 31 Desember 2020 yang pelaksanaannya adalah di Desa Dayakan Kecamatan Badegan Kabupaten Ponorogo.

\section{Pihak yang Terlibat}

Dalam menjalakan kegiatan ini perlu adanya peran aktif dari masyarakat Desa Dayakan, Perangkat Desa, Tokoh Agama, Ketua RT dan RW, kelompok karang taruna, dan kelompok PKK yang ada di Desa Dayakan. Sasaran khusus adalah warga Dusun Sekarputih dan Kliyur di Desa Dayakan.

\section{Langkah Pelaksanaan}

Kondisi awal masyarakat dalam hal mitigasi bencana belum begitu teredukasi dan tersadarkan akan pentingnya menjaga alam dan mencegah penggundulan hutan agar tidak terjadi bencana tanah longsor dan tanah longsor. Kemudian penanggulangan jika terjadi bencana yang dilakukan masyarakat masih secara konvensional jadi belum ada kecepatan penyampaian informasi jika terjadi masyarakat. Langkah yang dilakukan selama menjalankan kegiatan adalah: (a) Sosialisasi Progam, (b) Pembentukan Tim DMC (c) Pembuatan Aplikasi DMC, (d) Pengenalan Penggunaan Aplikasi, (e) Lokakarya dan Launching Aplikasi, dan (f) Evaluasi dan Monitoring

\section{HASIL DAN PEMBAHASAN}

Desa Dayakan memiliki potensi kekayaan alam yang luar biasa, berupa pemandangan dan suasananya yang sejuk. Hal tersebut dikarenakan Desa Dayakan memiliki letak geografis area pegunungan dan perbukitan. Dengan letak geografi tersebut Desa Dayakan berpotensi untuk terjadi Bencana alam tanah longsor. Kemudian bencana yang terjadi setiap tahun dan setiap musim kemarau adalah bencana kekeringan yang menimpa dan dirasakan hampir satu desa.

Berdasarkan langkah kegiatan yang telah dirancang oleh tim pelaksana kegiatan pengabdian masyarakat, maka diperoleh hasil sebagai berikut:

a. Sosialisasi kegiatan

Dalam tahap ini masyarakat disosialisasikan progam DMC dan pentingnya mitigasi bencana, sosialiasai dilakukan sebanyak dua kali agar masyarakat lebih memahami bentuk aplikasi, dan pentingnya dalam mitigasi bencana bagi Desa Dayakan.

Sosialisasi pertama dilaksanakan pada 9 Juli 2020 bertempat di Balai Desa Dayakan bersama kepala desa dan seluruh staf yang ada di Desa Dayakan. Sosialisasi berisi tentang maksud acara dan kegiatan yang akan dilaksanakan di Desa Dayakan. Sedangkan sosialisasi kedua dilaksanakan pada 1 Agustus dengan peserta sejumlah 35 orang yang terdiri dari 6 orang dari unsur pemerintah desa, 4 kepala dusun yaitu Dusun Jurang Sempu, Sekar Putih, Kliyur, dan Watu Agung, 15 orang sebagai perwakilan kelompok karang taruna dan 10 orang dari tim taruna tangguh bencana (Tagana). Pada sosialisasi kedua ini disampaikan tentang hal teknis terkait dengan pengenalan aplikasi yang akan dibuat dan berbagai tahapan yang akan dilaksanakan dalam kegiatan ini.

b. Pembentukan tim DMC

Tim DMC dibentuk berjumlahkan 28 Orang, dan diketuai oleh Bapak Ginanto selaku Sekretaris Desa Dayakan. Tim DMC bertugas untuk menjadi pelopor dan penggerak mitigasi bencana di Desa Dayakan dan sebagai pengelola aplikasi DMC yang nantinya digunakan untuk membantu dalam proses mitigasi bencana. 


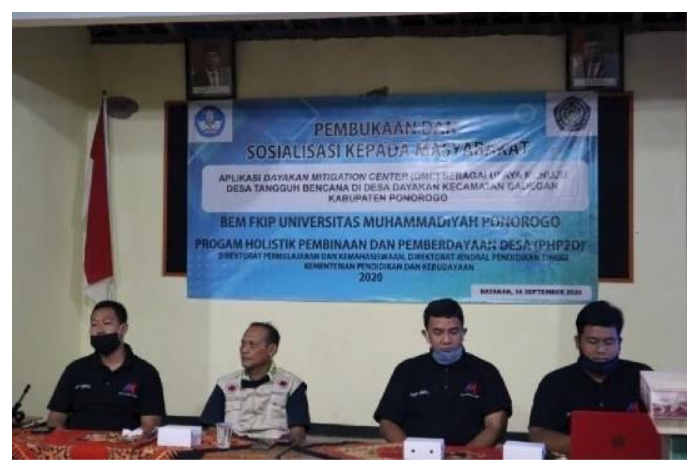

Gambar 1. Sosialisasi kegiatan bersama masyarakat

c. Pembuatan Aplikasi

Aplikasi DMC telah diunggah di Playstore sejak November 2020 dengan alamat https://play.google.com/store/apps/details?i $d=$ com.karyakan.dayakanmitigationcente.

Fitur yang tersedia dalam Aplikasi ini adalah fitur kenal bencana, cegah bencana, lapor bencana, berita BPBD (tersambung otomatis dengan BPBD Ponorogo), Sistem Informasi Geografis (SIG) Desa Dayakan, Hubungi (menghubungi admin), dan fitur panic button (untuk pelaporan cepat). Kemudian dalam mengatur aplikasi terdapat aplikasi admin berbasis web yang terintegrasi secara cepat (realtime).

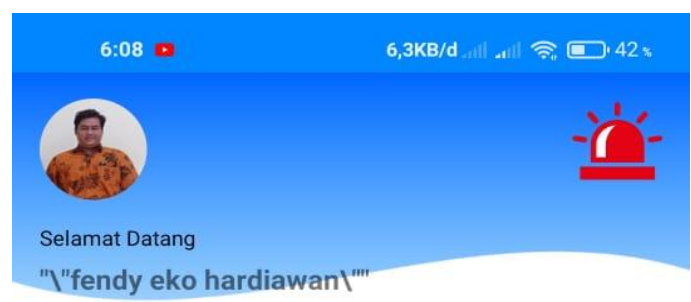

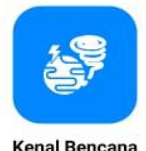

Kenal Bencana

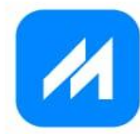

Berita BPBD

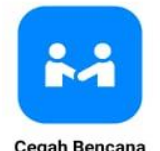

Cegah Bencana

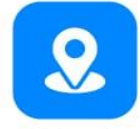

SIG Dayakan
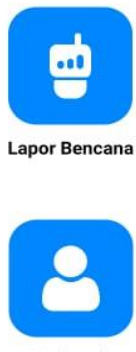

Hubungi
Gambar 2. Fitur aplikasi DMC

d. Pengenalan Penggunaan Aplikasi

Dalam rangka penggunaan yang maksimal untuk aplikasi DMC kepada masyarakat, maka tim melakukan pengenalan dan sosialisasi penggunaan aplikasi DMC kepada masyarakat khususnya di Dusun Sekarputih dan Kliyur di Desa Dayakan. Sosialisasi ini dilaksanakan dengan bebarengan kegiatan yang sudah lazim dilaksanakan oleh masyarakat, seperti kegiatan arisan, pertemuan PKK, atau rutinan jamaah mengaji. Adapun tahap dari penggunaan aplikasi DMC adalah sebagai berikut:

1. Pendaftar harus mendaftarkan akun pada aplikasi DMC dan mempunyai email aktif

2. Setelah mendapatkan email pendaftaran, pendaftar bisa masuk ke aplikasi melalui pengisian username dan password

3. Pengisian username dan password berhasil maka pendaftar dapat masuk pada aplikasi dan dapat mengakses fitur yang ada di dalamnya, diantaranya: kenal bencana, cegah bencana, lapor bencana, berita BPBD, SIG Dayakan, dan hubungi.

4. Jika pendaftar memilih hubungi maka langsung terhubung dengan admin DMC yang kemudian akan dihubungkan langsung dengan instansi yang dibutuhkan, seperti pemerintah desa, kantor polisi, puskesmas, atau BPBD.

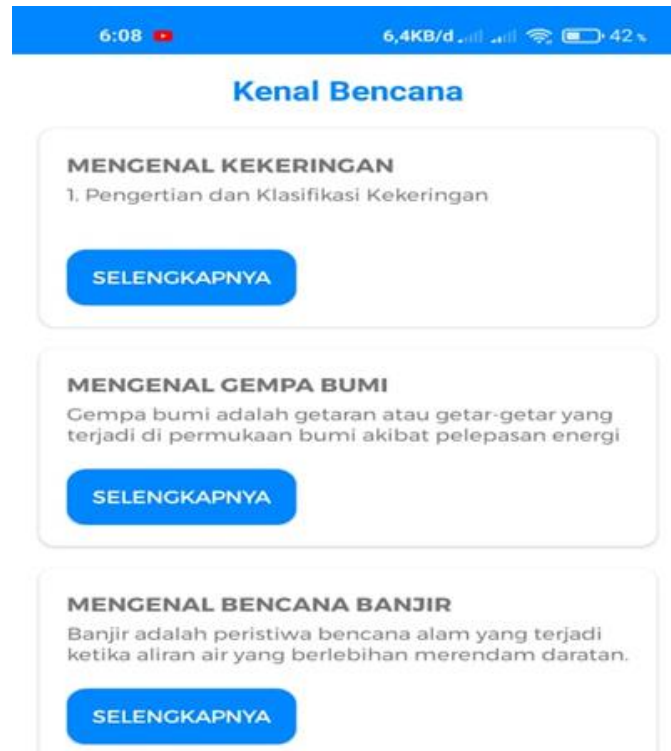

Gambar 3. Isian dalam fitur Kenal Bencana di aplikasi DMC

\section{e. Launching Aplikasi}

Kegiatan launching aplikasi DMC menghadirkan stakeholder ditingkat kecamatan hingga kabupaten, diantaranya kepolisian, TNI, kecamatan, puskesmas, dan pihak perhutani. Aplikasi DMC ini diharapkan akan membawa perubahan besar dalam mitigasi bencana di Desa Dayakan dan 
menjadikan Desa Dayakan sebagai Smart Village seperti yang disampaikan oleh kepala desa Desa Dayakan, Bapak Saroni. Hal ini juga dan besar harapan aplikasi DMC ini yang merupakan aplikasi mitigasi bencana satu-satunya di Ponorogo dapat di aplikasikan di seluruh desa rawan bencana di Ponorogo.

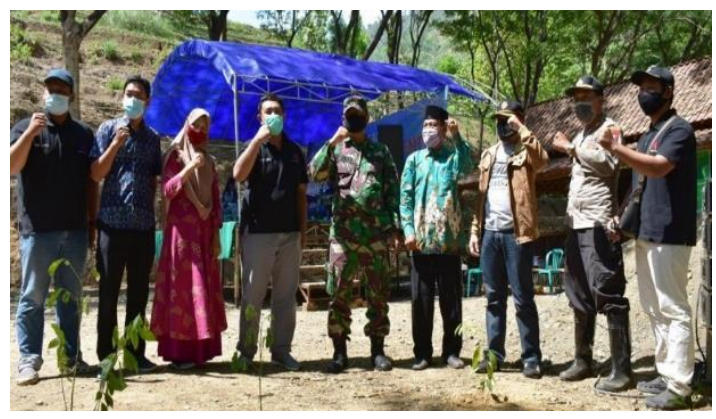

Gambar 3. Launching aplikasi DMC

f. Evaluasi dan Monitoring

Kegiatan evaluasi dilakukan setiap pra kegiatan berlangsung yang berguna untuk memperbaiki dan menyiapkan progamprogam berikutnya agar lebih baik. Evaluasi dilakukan bersama antara tim pelaksana dengan pihak pemerintah desa dan kecamatan. Adapun ada beberapa catatan dari hasil evaluasi bersama yang dilakukan, yaitu: (1) pelaksanaan koordinasi dengan pihak terkait seperti polsek, koramil, puskesmas, dan jaringan radio komunitas, (2) proses pendampingan penggunaan aplikasi secara berkala harus dilakukan, dan (3) belum semua dusun ada sinyal yang baik jadi dalam pelaksanaannya pemerintah desa mengharapkan kontinyuitas dalam kegiatan ini agar semua masyarakat dapat merubah cara pandang tentang bencana.

Sedangkan monitoring kegiatan juga telah dilaksanakan oleh pihak internal dan eksternal, yaitu sebagai pihak internal LPPM Universitas Muhammadiyah Ponorogo dan pihak eksternal yaitu pihak Direktorat Pembelajaran dan Kemahasiswaan Kementerian Pendidikan dan Kebudayaan Republik Indonesia. Dalam kesimpulannya pihak internal LPPM Universitas Muhammadiyah Ponorogo mendorong kepada mahasiswa untuk terus berinovasi dan bermanfaat untuk masyarakat salah satunya dengan pelaksanaan kegiatan positif seperti hal ini, sedangkan pihak Direktorat Pembelajaran dan Kemahasiswaan Kementerian Pendidikan dan Kebudayaan
Republik Indonesia memberikan arahan bahwa para pelaksana program harus menjaga keberlangsungan aplikasi ini dengan baik karena dapat membantu pemerintah desa dalam mempercepat informasi adanya bencana yang sedang terjadi, selain itu pelaksana diharapkan dapat memperluas aktivitasnya pada bidang lain diluar kebencanaan seperti pendidikan dan pemberdayaan ekonomi masyarakat.

Hasil dari pelaksanaan kegiatan dapat dirasakan secara jangka panjang, kegiatan yang dilakukan pada 1 Juli 2020 sampai dengan 31 Desember 2020 hanya sampai dengan pelaksanaan program aplikasi. Meskipun demikian sampai dengan launching aplikasi DMC selesai dilaksanakan sudah ada 45 orang terigester pada aplikasi DMC, adapun persebaran pada tiap dusunnya adalah: Dusun Jurang Sempu 10 orang, Sekar Putih 8 orang, Kliyur 12 orang, dan Watu Agung 15 orang.

Pembuataan aplikasi yang dilaksanakan ini tidak akan bisa dilakukan jika tidak ada kolaborasi dari berbagai pihak terkait dengan pengembangan sistem aplikasi. Kolaborasi yang dilakukan dalam kegiatan ini pada hakekatnya bertujuan untuk mencapai tujuan bersama dan saling membantu antara satu pihak dengan pihak lainnya. Hal ini sesuai dengan yang disampaikan oleh Syani bahwa kolaborasi merupakan suatu bentuk proses sosial yang didalamnya terdapat aktivitas tertentu yang ditujukan untuk mencapai tujuan bersama dan saling membantu serta mmahami aktivitas dari masing-masing pihak (Syani, 2012).

Selanjutnya pada pelaksanaannya terdapat beberapa variabel yang diketahui dapat menjadi indikator keberhasilan dalam pelaksanaan kegiatan di Desa Dayakan, yaitu adanya pembagian kerja antar lembaga, struktur kelembagaan yang jelas, dan koordinasi yang secara intens dilaksanakan antara pelaksana kegiatan dengan pihak pemerintah desa, karang taruna, dan tim Tagana hal ini sesuai dengan yang disampaikan oleh Graddy bahwa kolaborasi akan berhasil jika variabel tersebut dapat terlaksana dengan baik (Amaliah, 2021).

\section{SIMPULAN DAN SARAN}

Berdasarkan kegiatan yang telah dilaksanakan oleh Tim dari Fakultas Keguruan dan Ilmu Pendidikan Universitas 
Muhammadiyah Ponorogo, sampai dengan rentang pelaksanaan kegiatan selesai semua berjalan sesuai dengan agenda kegiatan yang direncanakan. Setelah launching dilaksanakan para masyarakat terutama dari unsur pemerintahan dan tim tagana segera menyesuaikan dengan penggunaan aplikasi DMC. Hasil dari pelaksanaan kegiatan dapat dirasakan secara jangka panjang, kegiatan yang dilakukan pada 1 Juli 2020 sampai dengan 31 Desember 2020 hanya sampai dengan pelaksanaan program aplikasi. Meskipun demikian sampai dengan launching aplikasi DMC selesai dilaksanakan sudah ada 45 orang terigester pada aplikasi DMC. Rencana lebih lanjut terkait dengan keberlanjutan kegiatan adalah adanya kontrol administrator dalam aplikasi yang akan dilaksanakan setiap 3 bulan sekali oleh Tim dari Fakultas Keguruan dan Ilmu Pendidikan.

Selanjutnya saran yang diberikan oleh tim adalah adanya keberlanjutan dari kegiatan ini, adanya bantuan anggaran dari pemerintah daerah untuk modifikasi aplikasi sangat diharapkan sehingga maintenance dapat dilaksanakan secara berkala. Selain itu diharapkan aplikasi ini dapat dibuat lagi untuk desa lain yang ada di Kecamatan Badegan atau Kabupaten Ponorogo sehingga aplikasi ini bisa memberikan manfaat yang besar dalam upaya mitigasi bencana di Kabupaten Ponorogo.

\section{UCAPAN TERIMA KASIH}

Terimakasih kami sampaikan kepada Direktorat Pembelajaran dan Kemahasiswaan Kementerian Pendidikan dan Kebudayaan Republik Indonesia yang telah memberikan dana untuk kegiatan ini melalui Program Holistik Pembinaan dan Pemberdayaan Desa (PHP2D)

\section{DAFTAR PUSTAKA}

Amaliah, Y. (2021). Collaborative Governance dalam Penanggulangan Kemiskinan di Kabupaten Barru. Universitas Hasanuddin.

Badan Geologi, K. E. (2020, March 23). Tanggapan Kejadian Banjir Bandang Di Desa Dayakan, Kecamatan Badegan, Kabupaten Ponorogo, Provinsi Jawa Timur . https://vsi.esdm.go.id/index.php/gerakantanah/kejadian-gerakan-tanah/3010tanggapan-kejadian-banjir-bandang-di-desadayakan-kecamatan-badegan-kabupaten- ponorogo-provinsi-jawa-timur

BPBD Kabupaten Ponorogo. (2020). Potensi Bencana di Kabupaten Ponorogo.

Mahardhani, A. J. (2020). Menjadi Warga Negara yang Baik pada Masa Pandemi Covid-19: Persprektif Kenormalan Baru. Jurnal Pancasila Dan Kewarganegaraan. https://doi.org/10.24269/jpk.v5.n2.2020.pp6 5-76

Muhammad, F., Hadi, A., \& Irfan, D. (2018). PENGEMBANGAN SISTEM INFORMASI PANDUAN MITIGASI BENCANA ALAM PROVINSI SUMATERA BARAT BERBASIS ANDROID. Jurnal Teknologi Informasi Dan Pendidikan. https://doi.org/10.24036/tip.v11i1.93

Mukharomah, E. (2020, March 20). Desa Dayakan Ponorogo Longsor, 90 Warga Mengungsi https://www.timesindonesia.co.id/read/news /258231/desa-dayakan-ponorogo-longsor90-warga-mengungsi

Oktari, R. S. (2019). Peningkatan Kapasitas Desa Tangguh Bencana. Jurnal Pengabdian Kepada Masyarakat (Indonesian Journal of Community Engagement). https://doi.org/10.22146/jpkm.29960

Pebrianti, C. (2020, March 19). Banjir Bandang Isolir Warga Satu Dusun di Ponorogo. https://news.detik.com/berita-jawa-timur/d4947080/banjir-bandang-isolir-warga-satudusun-di-ponorogo

Peraturan Pemerintah RI No 21 Tahun 2008. (n.d.). Retrieved January 19, 2021, from https://bnpb.go.id/ppid/file/PP_No._21_Th_ 2008.pdf

Pratomo, Y. (2019, July 17). Aplikasi Mitigasi Bencana Diklaim Bisa Kurangi Jumlah Korban.

Https://Tekno.Kompas.Com/Read/2019/07/ 17/18170077/Aplikasi-Mitigasi-BencanaDiklaim-Bisa-Kurangi-Jumlah-Korban. https://tekno.kompas.com/read/2019/07/17/ 18170077/aplikasi-mitigasi-bencanadiklaim-bisa-kurangi-jumlah-korban

Ruswandi, R., Saefuddin, A., Mangkuprawira, S., Riani, E., \& Kardono, P. (2008). Identifikasi Potensi Bencana Alam dan Upaya Mitigasi yang Paling Sesuai Diterapkan di Pesisir Indramayu dan Ciamis. Jurnal RISET Geologi Dan Pertambangan. https://doi.org/10.14203/risetgeotam2008.v1 8.12

Sukirman, S., Reza, W. A., \& Sujalwo, S. (2019). Media Interaktif Berbasis Virtual 
Reality untuk Simulasi Bencana Alam Gempa Bumi dalam Lingkungan Maya. Khazanah Informatika: Jurnal Ilmu Komputer Dan Informatika. https://doi.org/10.23917/khif.v5i1.8054

Sutedi, A. (2020). Rancang Bangun Aplikasi Pengidentifikasi Bencana dan Lokasi Aman Bencana Berbasis Media Sosial. Jurnal Algoritma.

https://doi.org/10.33364/algoritma/v.162.239
Syani, A. (2012). Sosiologi Skematika, Teori, dan Terapan. Bumi Aksara.

Wicaksono, G. S. (2020, January 7). Musim Hujan, di Ponorogo Masih Ada Daerah Kekurangan Air Bersih. https://jatimnet.com/musim-hujan-diponorogo-masih-ada-daerah-kekuranganair-bersih 